\title{
Promising Assessment of Vascular Function for Future Cardiovascular Events
}

\author{
Masato Kajikawa ${ }^{1}$ and Yukihito Higashi, ${ }^{1,2}$
}

${ }^{1}$ Division of Regeneration and Medicine, Medical Center for Translational and Clinical Research, Hiroshima University Hospital, Hiroshima, Japan

${ }^{2}$ Department of Cardiovascular Regeneration and Medicine, Research Institute for Radiation Biology and Medicine, Hiroshima University, Hiroshima, Japan

\section{See article vol. 28: 000-000}

Atherosclerotic cardiovascular disease is the leading cause of death worldwide. Although the prevention and treatment of cardiovascular disease have significantly advanced, the residual risk of cardiovascular events remains high in patients with established coronary, cerebrovascular, and peripheral artery disease ${ }^{1)}$. Current guidelines recommend intensive therapies for secondary prevention in patients with high risk of cardiovascular events ${ }^{1-3)}$. Therefore, it is important to identify patients with high risk of cardiovascular events who may benefit from intensive therapies to minimize the subsequent risk.

Recently, noninvasive vascular function tests have been developed to estimate vascular damage and risk of cardiovascular events. Flow-mediated vasodilation (FMD) as a marker of endothelial function and brachial-ankle pulse wave velocity (baPWV) as a marker of arterial stiffness (a marker of medial layer function) are currently in clinical use to evaluate vascular function ${ }^{4,5)}$. Previous studies have shown that both FMD and baPWV are independent predictors of future cardiovascular events $4,6,7)$. Since FMD and baPWV reflect different aspects of vascular function, it is expected that the combination of FMD and baPWV would be a more useful marker to evaluate the degree of vascular dysfunction and would improve the predictive value of future cardiovascular events compared with measurement of FMD or baPWV alone. Several investigators have shown that combination of FMD and baPWV is useful as a surrogate marker of future cardiovascular events ${ }^{8,9)}$. However, whether repeated measurements of FMD and baPWV provide additional information on the cardiovascular risk stratification is still unknown. It is unclear whether changes in FMD and baPWV after optimal treatment of cardiovascular risk factors could be useful marker of treatment effectiveness.

In this issue of the Journal of Atherosclerosis and Thrombosis, Nakamura and colleagues evaluated the improvement in FMD and baPWV on the risk of cardiovascular events in 323 patients with coronary artery disease who had impaired vascular function (defined FMD $<5.5 \%$ and baPWV $>1440 \mathrm{~cm} /$ sec ${ }^{10)}$. After 24 weeks of optimal medical treatment for traditional cardiovascular risk factors, follow-up measurements of FMD and baPWV were performed. Patients were divided into three groups: patients with improvement in FMD and baPWV, patients with improvement in either FMD or baPWV, and patients without improvement in FMD and baPWV. During a median follow-up period of 35 months, subsequent cardiovascular events occurred in 72 patients. The Kaplan-Meier curves for cardiovascular events among the three groups were significantly different. After adjustment for various confounders, patients with improvement in FMD and baPWV were associated with a reduced risk of cardiovascular events compared with patients without improvement in FMD and baPWV. In addition, their results have shown that the repeated measurements of FMD and baPWV add predictive value to the traditional risk factors and the achievement of therapeutic goals of cardiovascular risk factors. The results of this study support that repeated measurements of FMD and baPWV might help to identify those patients being at higher risk for cardiovascular events and might be a useful marker of treatment effectiveness.

Although Nakamura et al. have clearly shown

Address for correspondence: Masato Kajikawa, Division of Regeneration and Medicine, Medical Center for Translational and Clinical Research, Hiroshima University Hospital, 1-2-3 Kasumi, Minami-ku, Hiroshima 734-8551, Japan

Received: October 28, 2020 Accepted for publication: October 28, 2020

Copyright@2021 Japan Atherosclerosis Society

This article is distributed under the terms of the latest version of CC BY-NC-SA defined by the Creative Commons Attribution License. 
Table 1. Estimated criteria for vascular dysfunction and its border zone

\begin{tabular}{lccc}
\hline & \multicolumn{3}{c}{ Vascular function } \\
\cline { 2 - 4 } & Normal & Borderline & Abnormal \\
\hline FMD $\%$ & $\geq 7.0$ & $\geq 4.0$ and $<7.0$ & $<4.0$ \\
baPWV, $\mathrm{cm} / \mathrm{sec}$ & $<1400$ & $\geq 1400$ and $<1800$ & $\geq 1800$ \\
\hline
\end{tabular}

FMD, flow-mediated vasodilation; baPWV, brachial-ankle pulse wave velocity.

that the predictive value of the repeated measurements of FMD and baPWV, the cutoff values of FMD and baPWV to identify which patients need recommendation for intensive treatment remain unknown. This study enrolled patients with FMD of less than 5.5\% and baPWV of more than $1440 \mathrm{~cm} / \mathrm{sec}$ with implementation of optimal therapy. Recently, the Japan Society for Vascular Failure proposed the criteria of FMD and baPWV for normal, borderline, and abnormal vascular functions (Table 1$)^{4)}$. The differences in cutoff value of vascular dysfunction might affect the predictive value of the repeated measurements of FMD and baPWV. In addition, associations between the repeated measurements of vascular function and the incidence of cardiovascular event in a specific population such as age group (the younger adults, the elderly), gender, and patients without history of cardiovascular events are still unknown. Further studies are needed to justify and validate the cutoff values of FMD and baPWV in high- and low-risk groups for clinical use.

\section{Acknowledgements}

None.

\section{Sources of Funding}

This work was supported by JSPS KAKENHI (Grant Number JP19K17599) and a Grant in Aid of Japanese Arteriosclerosis Prevention Fund.

\section{Disclosures}

None.

\section{References}

1) Kinoshita $M$, Yokote $K$, Arai $H$, Iida $M$, Ishigaki $Y$, Ishibashi S, Umemoto S, Egusa G, Ohmura H, Okamura T, Kihara S, Koba S, Saito I, Shoji T, Daida H, Tsukamoto K, Deguchi J, Dohi S, Dobashi K, Hamaguchi H, Hara M, Hiro T, Biro S, Fujioka Y, Maruyama C, Miyamoto Y, Murakami Y, Yokode M, Yoshida H, Rakugi H, Wakatsuki A and Yamashita S.
Japan Atherosclerosis Society (JAS) Guidelines for Prevention of Atherosclerotic Cardiovascular Diseases 2017. J Atheroscler Thromb, 2018; 25: 846-984

2) Umemura $S$, Arima $H$, Arima $S$, Asayama $K$, Dohi $Y$, Hirooka Y, Horio T, Hoshide S, Ikeda S, Ishimitsu T, Ito M, Ito S, Iwashima Y, Kai H, Kamide K, Kanno Y, Kashihara N, Kawano Y, Kikuchi T, Kitamura K, Kitazono T, Kohara K, Kudo M, Kumagai H, Matsumura K, Matsuura H, Miura K, Mukoyama M, Nakamura S, Ohkubo T, Ohya Y, Okura T, Rakugi H, Saitoh S, Shibata H, Shimosawa T, Suzuki H, Takahashi S, Tamura K, Tomiyama $\mathrm{H}$, Tsuchihashi T, Ueda S, Uehara Y, Urata H and Hirawa N. The Japanese Society of Hypertension Guidelines for the Management of Hypertension (JSH 2019). Hypertens Res, 2019; 42: 1235-1481

3) Grundy SM, Stone NJ, Bailey AL, Beam C, Birtcher KK, Blumenthal RS, Braun LT, de Ferranti S, FaiellaTommasino J, Forman DE, Goldberg R, Heidenreich PA, Hlatky MA, Jones DW, Lloyd-Jones D, Lopez-Pajares N, Ndumele CE, Orringer CE, Peralta CA, Saseen JJ, Smith SC, Jr., Sperling L, Virani SS and Yeboah J. 2018 AHA/ ACC/AACVPR/AAPA/ABC/ACPM/ADA/AGS/APhA/ ASPC/NLA/PCNA Guideline on the Management of Blood Cholesterol: A Report of the American College of Cardiology/American Heart Association Task Force on Clinical Practice Guidelines. Circulation, 2019; 139: e1082-e1143

4) Tanaka A, Tomiyama $H$, Maruhashi $T$, Matsuzawa $Y$, Miyoshi T, Kabutoya T, Kario K, Sugiyama S, Munakata M, Ito H, Ueda S, Vlachopoulos C, Higashi Y, Inoue T and Node K. Physiological Diagnostic Criteria for Vascular Failure. Hypertension, 2018; 72: 1060-1071

5) Higashi $Y$, Noma $K$, Yoshizumi $M$ and Kihara $Y$. Endothelial function and oxidative stress in cardiovascular diseases. Circ J, 2009; 73: 411-418

6) Kajikawa M, Maruhashi T, Hida E, Iwamoto Y, Matsumoto T, Iwamoto A, Oda N, Kishimoto S, Matsui S, Hidaka T, Kihara Y, Chayama K, Goto C, Aibara Y, Nakashima A, Noma K and Higashi Y. Combination of Flow-Mediated Vasodilation and Nitroglycerine-Induced Vasodilation Is More Effective for Prediction of Cardiovascular Events. Hypertension, 2016; 67: 10451052

7) Ohkuma T, Ninomiya T, Tomiyama H, Kario K, Hoshide S, Kita Y, Inoguchi T, Maeda Y, Kohara K, Tabara Y, Nakamura M, Ohkubo T, Watada $H$, Munakata $M$, Ohishi M, Ito N, Nakamura M, Shoji T, Vlachopoulos C, Yamashina A; Collaborative Group for J-BAVEL (Japan Brachial-Ankle Pulse Wave Velocity Individual Participant Data Meta-Analysis of Prospective Studies). Brachial-

\section{Advance Publication Journal of Atherosclerosis and Thrombosis}


Ankle Pulse Wave Velocity and the Risk Prediction of Cardiovascular Disease. Hypertension, 2017; 69: 10451052

8) Maruhashi T, Soga J, Fujimura N, Idei N, Mikami S, Iwamoto Y, Iwamoto A, Kajikawa M, Matsumoto T, Oda N, Kishimoto S, Matsui S, Hashimoto H, Aibara Y, Mohamad Yusoff F, Hidaka T, Kihara Y, Chayama K, Noma K, Nakashima A, Goto C, Tomiyama H, Takase B, Kohro T, Suzuki T, Ishizu T, Ueda S, Yamazaki T, Furumoto T, Kario K, Inoue T, Koba S, Watanabe K, Takemoto Y, Hano T, Sata M, Ishibashi Y, Node K, Maemura K, Ohya Y, Furukawa T, Ito H, Ikeda $\mathrm{H}$, Yamashina A and Higashi Y. Endothelial Dysfunction, Increased Arterial Stiffness, and Cardiovascular Risk Prediction in Patients With Coronary Artery Disease: FMD-J (Flow-Mediated Dilation Japan) Study A. J Am
Heart Assoc, 2018; 7

9) Sugamata W, Nakamura T, Uematsu M, Kitta Y, Fujioka D, Saito Y, Kawabata K, Obata JE, Watanabe Y, Watanabe $\mathrm{K}$ and Kugiyama K. Combined assessment of flowmediated dilation of the brachial artery and brachial-ankle pulse wave velocity improves the prediction of future coronary events in patients with chronic coronary artery disease. J Cardiol, 2014; 64: 179-184

10) Nakamura T, Uematsu M, Horikoshi T, Yoshizaki T, Kobayashi T, Saito Y, Watanabe Y, Nakamura K, Obata JE, Kugiyama K. Improvement in brachial endothelial vasomotor function and brachial-ankle pulse wave velocity reduces the residual risk for cardiovascular events after optimal medical treatment in patients with coronary artery disease. J Atheroscler Thromb, 2020 (in press). DOI: http: //doi.org/10.5551/jat.57562 